\title{
ELECTROSTATIC SHAPE SEPARATION OF FLAKE MICA FROM PEGMATITES
}

\author{
AL. YUGA ${ }^{\star}$, L. DASCALESCU ${ }^{\dagger}$, R. MORAR ${ }^{\star}$, A. SAMUILA ${ }^{\star}$ \\ AND I. CUGLESAN ${ }^{\ddagger}$ \\ ${ }^{\star}$ Technical University of Cluj-Napoca, 15 C. Daicoviciu St., Cluj-Napoca, \\ 3400 Romania \\ $\dagger_{\text {Laboratoire d'Electrostatique et de Materiaux Dielectriques C.N.R.S., }}$ \\ B.P. 166, 38042 Grenoble Cedex 9, France

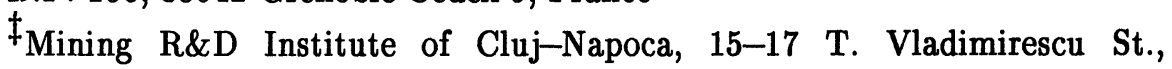 \\ Cluj-Napoca, 3400 Romania
}

(Received November 11, 1994, accepted January 12, 1995)

\begin{abstract}
Electrostatic shape separation was considered to be an adequate technique for processing a particulate mixture of flake mica and isometric granules of feldspar and quartz. The authors carried out extensive laboratory experiments to concentrate flake muscovite from a pegmatitic product with content of 50 to $65 \%$ of mica. Prior to electroseparation, the granular material was dried and vibrating screens were employed to obtain two fractions: $+1 \mathrm{~mm}$ (which represented more than $70 \%$ of the feed), and $-1+0.315 \mathrm{~mm}$. Each fraction was then treated in the corona-field roll-type separator. In the first group of experiments, two corona electrodes of opposite polarities were conveniently located relative to the grounded metallic roll carrier. The second group of experiments necessitated one corona electrode only, but the roll carrier was covered by a dielectric layer. These two electrostatic shape separation methods were discussed, based on a crude evaluation of the charges and forces which act on various constituents of the granular mixture. Mica concentrates with $45.47 \% \mathrm{SiO}_{2}$, $36.08 \% \mathrm{Al}_{2} \mathrm{O}_{3}$ and $10.4 \%\left(\mathrm{~K}_{2} \mathrm{O}+\mathrm{Na}_{2} \mathrm{O}\right)$ were obtained, using a two-stage electroseparation scheme. These products fulfill the requirements regarding the composition and the size distribution of the flake mica for several applications in the industry of electrical insulating materials.
\end{abstract}

\section{INTRODUCTION}

Electrostatic separation $[1,2]$ is the generic term for an important class of technologies for beneficiation of materials [3], extensively used for selective sorting 
of solid species by means of the electric forces which act on charged or polarised bodies. Such methods $[4,5]$ have seldom been employed to concentrate muscovite mica from mineral sands $[6,7,8]$. However, the increasing demand for mica flakes on the market of electroinsulating materials has determined a rising interest of mining industry towards developing suitable processing technologies for recovering this product from low-grade materials.

The research presented in this paper focused on the production of flake muscovite by processing a refuse material from the flotation flowsheet of pegmatite, a feldspar- and quartz-bearing mineral excavated at Muntele Rece in Cluj County, Romania. The aim was to obtain a concentrate of mica having physico-chemical characteristics required by the electroinsulating materials industry. Electrostatic shape separation was considered to be the most suitable technique for processing a granular mixture containing flake mica and isometric granules of feldspar and quartz. Two electroseparation methods have been tested in laboratory, prior to industrial application.

\section{MATERIALS}

The flotation flowsheet of the pegmatites excavated at Muntele Rece-Cluj (Romania) was designed for the production of feldspatic sand used as a flux in the ceramics industries. After crushing and grinding, the pegmatites are classified on a vibrating screen. The coarse (rejected) fraction from this operation contains relatively large amounts of flake mica.

This refuse material was considered for the electroseparation experiments after a supplementary sizing operation. Proportions if fractions $+1 \mathrm{~mm},-1+0.315 \mathrm{~mm}$ and $-0.315 \mathrm{~mm}$ (which was discarded) were 70:28:2, and varied slightly with the conditions of the feed. Chemical compositions of the first two fractions, labeled "sample \#1" and "sample \#2" were analysed with standard methods and the results are given in Table 1 . Composition of pure muscovite $\mathrm{H}_{2} \mathrm{KAl}_{3}\left(\mathrm{SiO}_{4}\right)_{3}$ is: $45.26 \% \mathrm{SiO}_{2}, 38.41 \% \mathrm{Al}_{2} \mathrm{O}_{3}, 11.83 \mathrm{~K}_{2} \mathrm{O}$ and $4.5 \% \mathrm{H}_{2} \mathrm{O}$.

Mineralogical analysis revealed that muscovite represented more than $65 \%$ in sample \#1 and almost $50 \%$ in sample \#2. The processed materials contained also feldspar, quartz and wood splinters in variable proportions. As all the constituents 
were non-magnetic and of almost similar specific density (muscovite $2950 \mathrm{~kg} / \mathrm{m}^{3}$, feldspar $2600 \mathrm{~kg} / \mathrm{m}^{3}$ and quartz $2650 \mathrm{~kg} / \mathrm{m}^{3}$ ), magnetic or gravity separation is not applicable, but electrostatic shape separation might be a suitable technique.

Table 1 Chemical composition of the samples

\begin{tabular}{||c|c|c|c|c|c|c|}
\hline \multirow{2}{*}{ Sample } & \multicolumn{7}{|c|}{ Composition (\%) } \\
\cline { 2 - 7 } & $\mathrm{SiO}_{2}$ & $\mathrm{Al}_{2} \mathrm{O}_{3}$ & $\mathrm{Fe}_{2} \mathrm{O}_{3}$ & $\mathrm{~K}_{2} \mathrm{O}$ & $\mathrm{Na}_{2} \mathrm{O}$ & L.I. $^{\text {a) }}$ \\
\hline$\# 1(+1 \mathrm{~mm})$ & 49.30 & 33.33 & 1.85 & 8.40 & 1.30 & 4.82 \\
\hline $\begin{array}{c}\# 2(-1 \mathrm{~mm} \\
+0.315 \mathrm{~mm})\end{array}$ & 55.77 & 28.37 & 1.45 & 7.20 & 2.00 & 3.79 \\
\hline
\end{tabular}

a) L.I. = loss on ignition

\section{ELECTROSEPARATION METHODS}

The selective sorting of muscovite from feldspar and quartz was carried out on ELSEP laboratory electroseparator [9] equipped with an interchangeable roll-carrier electrode, connected to the ground, and with one or two high-voltage d.c. supplies, for the energisation of the corona electrodes. An electromagnetic vibratory feeder with an over-tray heater transfers the material from a hopper onto the surface of the rotating roll-carrier.

\section{(a) Method I: Two Corona Electrodes of Opposite Polarities}

ELSEP electroseparator (Fig. 1) was provided with a metallic roll electrode 6, $150 \mathrm{~mm}$ in diameter, and with two corona electrodes 7 and 8 , of opposite polarities [10]. The main (charging) corona electrode 8 was supplied with $+20 \mathrm{kV}$ direct voltage while the auxiliary (discharging) electrode 7 was energised at $-8 \mathrm{kV}$. The tips of both corona electrodes [11] were situated at $40 \mathrm{~mm}$ from the surface of the roll electrode. Sample \#1 was separated at a roll speed $n=200 \mathrm{rpm}$. The electroseparation trajectories of sample \#2 (Fig. 1a) were obtained at $n=250$ rpm. The photograph clearly illustrates that the feldspar and quartz granules 


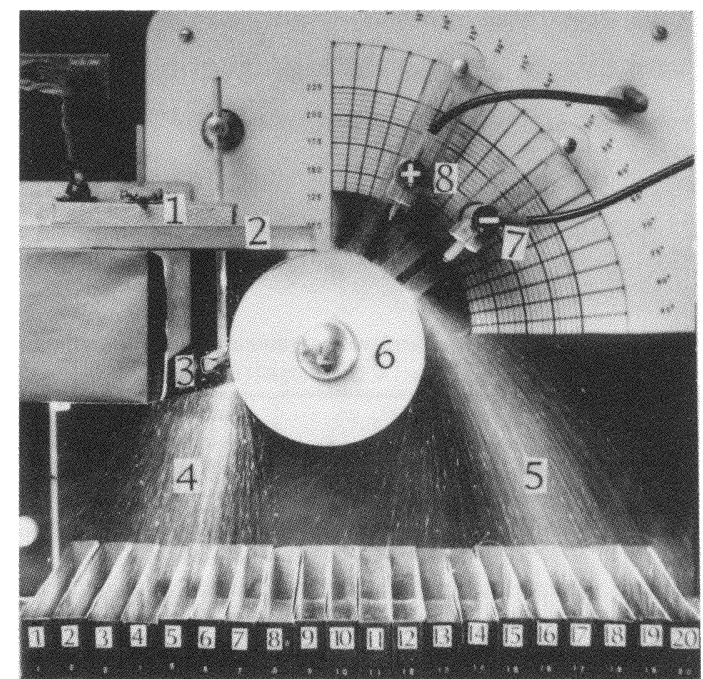

a

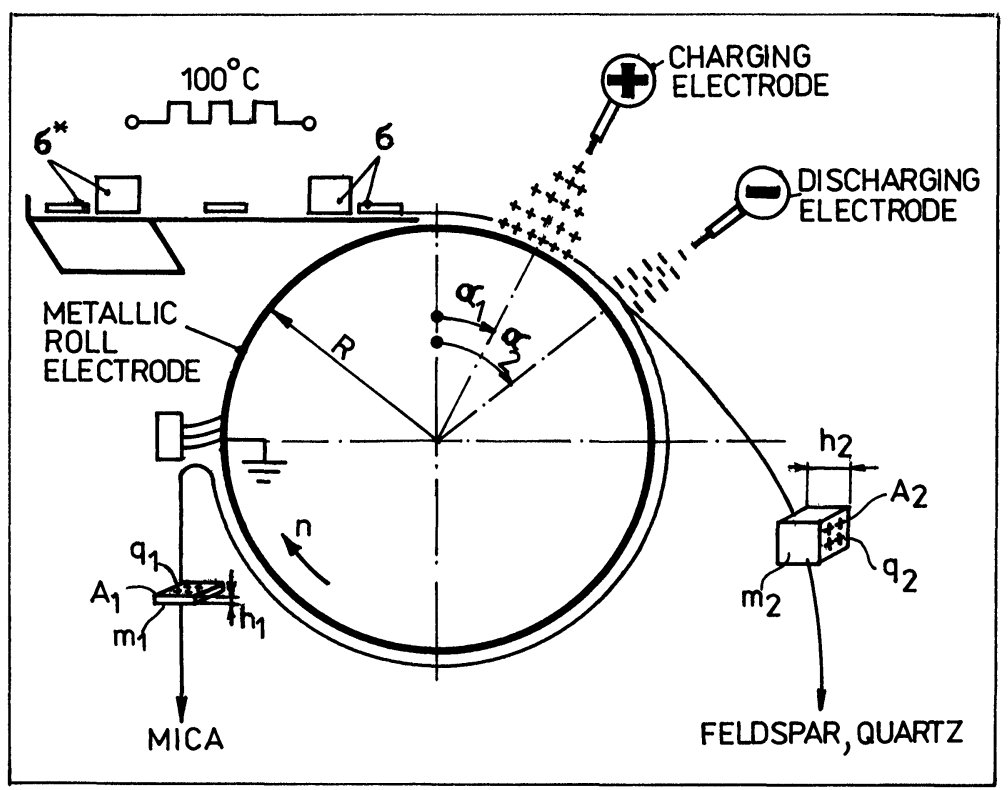

b

Fig. 1 Electroseparation of mica flakes from pegmatites: Method I: a-visualization of the separation trajectories of flake mica, quartz and feldspar (laboratory experiment with $50 \%$ mica flakes in the feed of size $-1+0.315 \mathrm{~mm}$ ).

b-schematic representation of the method: 1 -heater $(400 \mathrm{~W})$, for reducing the superficial moisture of the granules, 2-vibratory 
feeder, 3-brush, 4-flake mica trajectories, 5-quartz and feldspar trajectories, 6-grounded rotating roll carrier electrode (stainless steel, dia. $150 \mathrm{~mm}), 7$-auxiliary corona electrode $\left(\alpha_{2}=50^{\circ}\right)$, 8 -main corona charging electrode $\left(\alpha_{1}=25^{\circ}\right), m_{1}, q_{1}, A_{1}, h_{1}-$ mass, charge density,area and thickness of a flake of mica, $m_{2}, q_{2}$, $A_{2}, h_{2}$ - mass, charge density, area and thickness of a isometric granule of feldspar or quartz.

detached from the roll immediately after their exit from the main corona field and that the mica flakes were removed by a brush only after the $270^{\circ}$ journey with the rotating electrode.

The granular material is thermally conditioned by the over-tray heater on the vibratory feeder and then transferred onto the roll electrode. In the first corona field zone, all the granules are charged by "ion bombardment". The positively charged granules experience an electric image force $F_{\mathrm{i}}$ which keeps them "pinned" to the surface of the grounded rotating roll. The "pinning" effect is stronger on the flat flakes of mica, than on the quasi-isometric granules of feldspar or quartz. Thus, electrostatic shape separation takes place: the flakes of mica stuck to the rotating electrode while feldspar and quartz granules are driven away from it by the centrifugal force $F_{\mathrm{c}}$ as soon as the "pinning" factor $f$ is smaller than unity:

$$
\mathrm{f}=\mathrm{F}_{\mathrm{i}} / \mathrm{F}_{\mathrm{c}}<1
$$

The second corona field zone, generated by the auxiliary electrode of negative polarity, favours the detachment of feldspar and quartz, and hence increases the purity of the recovered mica concentrate.

\section{(b) Method II: Dielectric-Covered Roll Carrier}

A glass cylinder having a $1 \mathrm{~mm}$-thick wall and the outer diameter $150 \mathrm{~mm}$ was employed as a rotating roll electrode (Fig. 2). The inner surface of the electrode was wrapped with aluminium foil and connected to the ground. The roll speed was $150 \mathrm{rpm}$ with sample \#1, and $200 \mathrm{rpm}$ with sample \#2. 


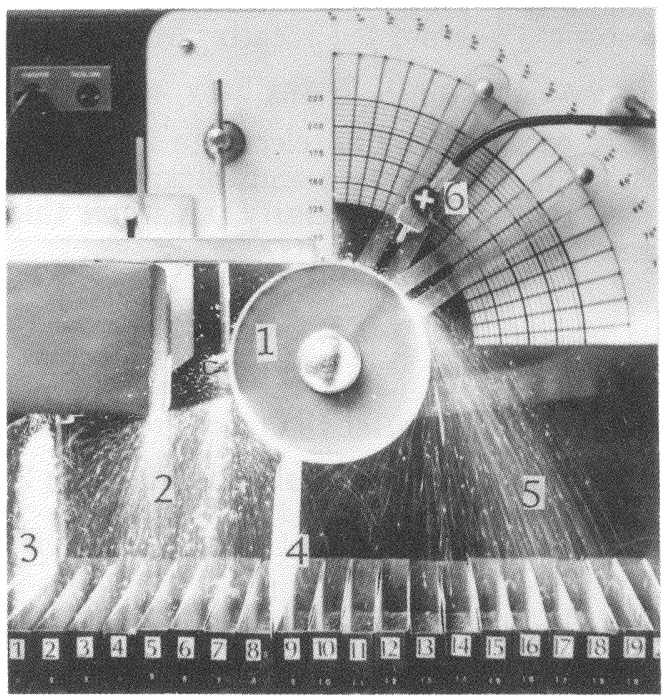

a

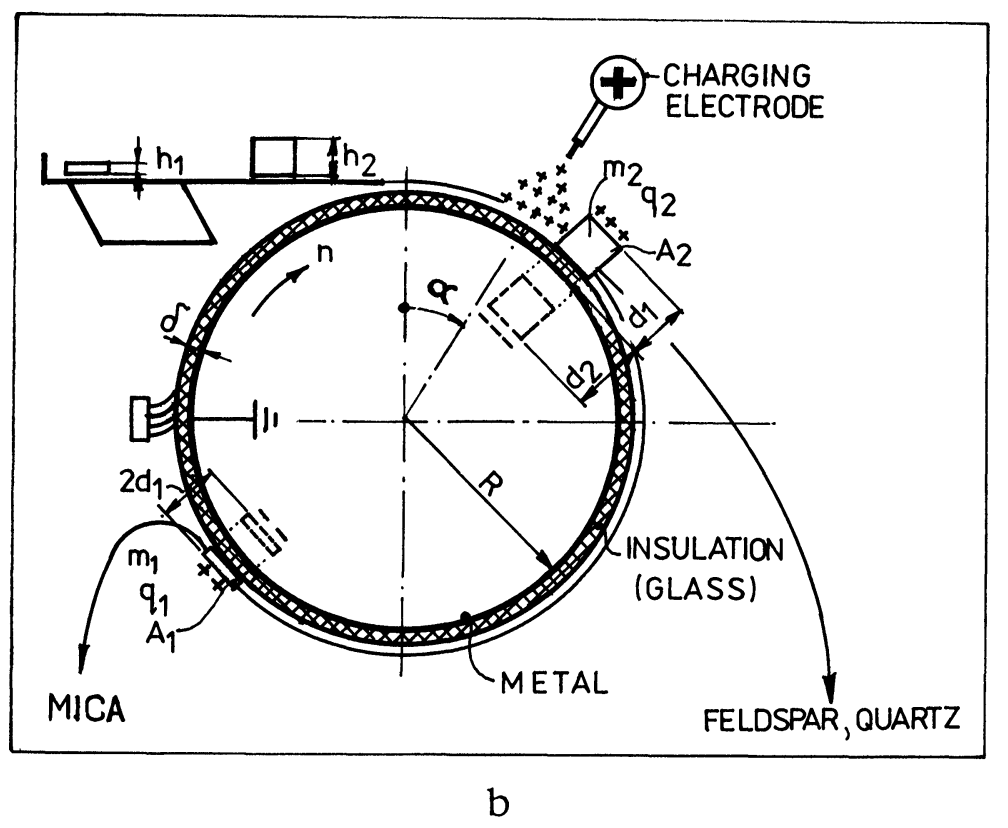

Fig. 2 Electroseparation of mica flakes from pegmatites - method II. a-visualisation of the separation trajectories of flake mica, quartz and feldspar (laboratory experiment with $50 \%$ mica flakes in the feed size $+1 \mathrm{~mm}$ )

b-schematic representation of the method 1-dielectric-coated rotating roll carrier electrode connected to the ground, 2-flake mica trajectories, 3-lateral wall of the 
collector, 4-splitter, 5-quartz and feldspar trajectories, 6-corona electrode $\left(\alpha=30^{\circ}\right), m_{1}, q_{1}, A_{1}, h_{1}$ - mass, charge density, area and thickness of a flake of mica, $m_{2}, q_{2}, A_{2}, h_{2}$ - mass,, charge density, area and thickness of an isometric granule of feldspar or quartz.

This method necessitated only one corona electrode energised at $+20 \mathrm{kV}$ (peak value). The corona-emitting tips of the electrode were located at $30 \mathrm{~mm}$ from the surface of the glass cylinder. No thermal conditioning of the material prior to electroseparation was needed in this case.

Part of the mica flakes detached from the roll-carrier before reaching the brush (Fig. 2a). This can be explained by the fact that the dielectric layer which covers the roll makes the electric image force smaller than with method I, at the same value of the charge acquired by a granule. The thinner is the dielectric layer, the better is the "pinning" effect.

The electric image force on the isometric feldspar and quartz granules is weaker than the centrifugal force so that they are easily thrown away from the rotating roll. Most of these particles detach from the roll carrier as soon as they exit from the corona field zone.

\section{RESULTS}

\section{Method I: Two Corona Electrodes of Opposite Polarities}

An effective removal of feldspar and quartz from the feed was achieved after two successive operations of electroseparation. In the case of sample \#1 (+1 mm), the concentrate resulted from the second stage of electroseparation (Table 2) had $3.83 \%$ less $\mathrm{SiO}_{2}$ and $2.75 \%$ more $\mathrm{Al}_{2} \mathrm{O}_{3}$ than the material that was introduced into the process (Table 1). Almost $66 \%$ of mica contained in the feed was collected as the final product. 
Table 2 Recovery of the flake mica and chemical composition of products obtained by two-stage electroseparation of sample \#1 (+1 mm)

\begin{tabular}{||c|c|c|c|c|c|c|c|}
\hline Product & Recovery & \multicolumn{7}{|c|}{ Composition (\%) } \\
\cline { 3 - 8 } & $(\%)$ & $\mathrm{SiO}_{2}$ & $\mathrm{Al}_{2} \mathrm{O}_{3}$ & $\mathrm{Fe}_{2} \mathrm{O}_{3}$ & $\mathrm{~K}_{2} \mathrm{O}$ & $\mathrm{Na}_{2} \mathrm{O}$ & L.I. \\
\hline Stage I & 73.00 & 46.10 & 34.91 & 2.17 & 8.50 & 1.45 & 5.08 \\
\hline Stage II & 65.70 & 45.47 & 36.08 & 2.06 & 9.30 & 1.10 & 4.98 \\
\hline \hline
\end{tabular}

The improvement of the chemical composition was even more spectacular for sample \#2 (-1 +0.315 mm) which contained larger amounts of impurities than the coarser sample: the concentration of $\mathrm{SiO}_{2}$ decreased by $8.71 \%$ while the content of $\mathrm{Al}_{2} \mathrm{O}_{3}$ increased by $7.16 \%$ compared to that in the feed (Table 3). Because of relatively high percentage of feldspar and quartz in this sample, the recovered mica flakes represented only $44.9 \%$ of the quantity of muscovite contained in the feed.

Table 3 Recovery of flake mica and chemical composition of the products obtained by two-stage electroseparation of sample \#2 (-1 +0.315 mm)

\begin{tabular}{||c|c|c|c|c|c|c|c|}
\hline Product & Recovery & \multicolumn{7}{|c|}{ Composition (\%) } \\
\cline { 3 - 8 } & $(\%)$ & $\mathrm{SiO}_{2}$ & $\mathrm{Al}_{2} \mathrm{O}_{3}$ & $\mathrm{Fe}_{2} \mathrm{O}_{3}$ & $\mathrm{~K}_{2} \mathrm{O}$ & $\mathrm{Na}_{2} \mathrm{O}$ & L.I. \\
\hline Stage I & 50.70 & 48.40 & 32.37 & 2.12 & 9.25 & 1.70 & 4.42 \\
\hline Stage II & 44.90 & 47.06 & 35.53 & 2.02 & 8.80 & 1.20 & 4.49 \\
\hline
\end{tabular}

The chemical composition of the mica concentrates thus obtained did not differ significantly from that of pure muscovite. The concentrations of $\mathrm{SiO}_{2}, \mathrm{Al}_{2} \mathrm{O}_{3}, \mathrm{~K}_{2} \mathrm{O}$ $+\mathrm{Na}_{2} \mathrm{O}$ in the $+1 \mathrm{~mm}$ final product were $45.47 \%, 36.08 \%$ and $10.4 \%$, respectively, which are close to the respective ideal values: $45.26 \%, 38.41 \%$ and $11.83 \%$. The mica concentrates were granulometrically homogeneous ( $91 \%$ of the flakes extracted from sample \#1 were in the 1 to $2 \mathrm{~mm}$ size range), and practically free of impurities. 
The tests validated the efficiency of the following flowsheet:

(1) the drying of the refuse from the table flotation of the granulated pegmatites $\left(300-400^{\circ} \mathrm{C}\right.$ in an oven)

(2) the sizing of the dry material (on $+1 \mathrm{~mm}$ and $+0.315 \mathrm{~mm}$ screens)

(3) the thermal conditioning of the material prior to electroseparation (100 $150^{\circ} \mathrm{C}$, with the heater above the tray of the vibratory feeder)

(4) electrostatic shape separation (on the roll-type separator, with two corona electrodes of opposite polarities).

\section{Method II: Dielectric-Covered Roll-Carrier}

The quantities of mica extracted by using Method II were slightly higher than those resulted from the one-stage electroseparation with Method I (Table 4).

Table 4 Mass of mica flakes recovered from samples \#1 and \#2, using two different methods of electrostatic shape separation

\begin{tabular}{|c|c|c|c|c|}
\hline \multirow{2}{*}{ Sample } & \multirow{2}{*}{ Method $^{(\mathrm{a})}$} & \multicolumn{3}{|c|}{ Mass (g) } \\
\cline { 3 - 5 } & & Mica flake & $\begin{array}{c}\text { Feldspar \& } \\
\text { quartz }\end{array}$ & Tailings \\
\hline $\begin{array}{c}\# 1 \\
(+1 \mathrm{~mm})\end{array}$ & I & 300.00 & 240.00 & 32.00 \\
\cline { 2 - 5 } & II & 322.00 & 220.00 & 31.00 \\
\hline $\begin{array}{c}\# 2 \\
(-1+0.315 \mathrm{~mm})\end{array}$ & I & 217.00 & 341.00 & 14.00 \\
\cline { 2 - 5 } & II & 256.00 & 263.00 & 42.00 \\
\hline
\end{tabular}

(a) Method I: two corona electrodes of opposite polarities Method II: grounded roll electrode covered with a dielectric layer (glass cylinder)

Figure 3 shows the shape and dimensions of products obtained from sample \#2. The mica fraction (Fig. 3a) was free of any impurities. The rejected fraction (Fig. 3b) contained a small amount of mica flakes besides the feldspar and quartz granules. Mica is elastic and most of the flakes in sample \#2 have the areas close to the upper limit of $1 \mathrm{~mm}^{2}$. Since feldspar and quartz are brittle these particles were isometric and of smaller dimensions than the mica flakes, usually in the lower limit of the respective granulometric class. 


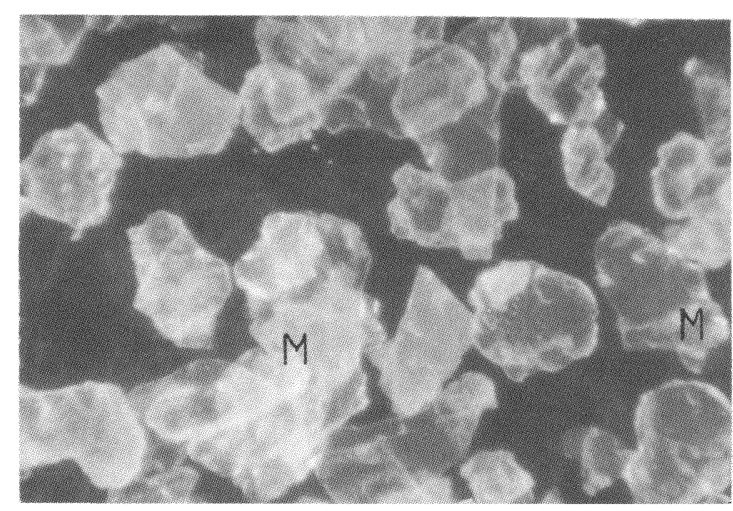

a

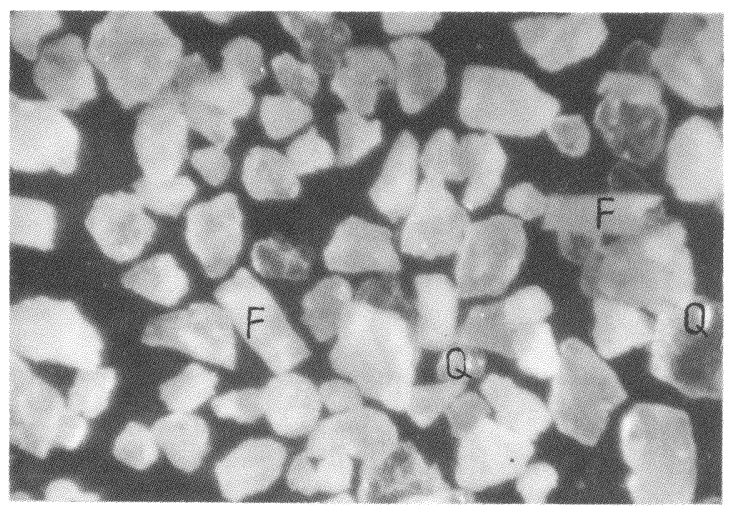

b

Fig. 3 Materials derived from electroseparation of sample \#2 using dielectric-coated roll-carrier. (a) flake mica (M) in an impurity-free product, (b) feldspar (F) and quartz (Q) granules in the rejected product (which also includes some mica)

\section{DISCUSSION}

The selective sorting of flake mica from pegmatites is a typical example of electrostatic shape separation. A crude evaluation of the forces involved in this 
separation process has been carried out under the following assumptions:

(1) each granule can be assimilated to a parallelepiped or a cylinder of area $A$ and height $h$; if $A_{1}$ and $h_{1}$ are the dimensions of the mica flake and $A_{2}$ and $h_{2}$ characterise the isometric granules of feldspar and quartz, then always $h_{1} / h_{2}<1$

(2) charge $Q$ imparted by ion bombardment accumulates only in the area $A$ of the face opposite to the contact surface between the granule and the roll-carrier

(3) distribution of charge $Q$ on the surface $A$ is uniform, with density $q=Q / A$

(4) granules are perfect electroinsulators (their electric conductivity is zero)

(5) dielectric layer which covers the roll carrier in Method II is of infinite electric resistivity

(6) granules of mica, feldspar and quartz have the same specific mass $\gamma$.

\section{(a) Discussion of Method I}

The electric image force $F_{\mathrm{i}}$ and the centrifugal force $F_{\mathrm{c}}$ which are involved in the separation process are given by the following formulae:

$$
\begin{aligned}
& \left.F_{i}=(q A)^{2} /\left[4 \pi \epsilon_{0}(2 h)^{2}\right)\right] \\
& F_{c}=4 \pi^{2} n^{2} R \gamma A h
\end{aligned}
$$

where $n\left[\mathrm{~s}^{-1}\right]$ is the speed of rotation and $R[\mathrm{~m}]$ is the radius of the roll-carrier electrode. The pinning factor factor $f$ can be derived from eqs. (2) and (3) as:

$$
f=F_{i} / F_{c}=\left[q^{2} /\left(64 \pi^{3} \epsilon_{0} n^{2} R \gamma\right)\right] A / h^{3}
$$

The feasibility of shape separation transpires from the ratio of the pinning factors of flat $\left(f_{1}\right)$ and isometric $\left(f_{2}\right)$ granules:

$$
f_{1} / f_{2}=\left(q_{1} / q_{2}\right)^{2}\left(\gamma_{2} / \gamma_{1}\right)^{2}\left(A_{1} / A_{2}\right)\left(h_{2} / h_{1}\right)^{3}
$$

In accordance with assumptions (3) and (6), i.e. $\gamma_{2}=\gamma_{1}=\gamma$ and $k_{1}=k_{2}=k$, the 
ratio $f_{1} / f_{2}$ depends only on geometrical parameters of the two types of particles.

If the mica flakes and the feldspar or quartz particles have the same area $A$ exposed to the ion flux, but the ratio of their third dimensions is $h_{1} / h_{2}<1$, one can find that:

$$
f_{1} / f_{2}=1 /\left(h_{1} / h_{2}\right)^{3}
$$

For instance, if $h_{1} / h_{2}=1 / 3$, the pinning factor of the mica flakes is 27 times that of the other particles: $f_{1}=\left[1 /\left(h_{1} / h_{2}\right)^{3}\right] f_{2}=27 f_{2}$. This means that at the moment when the feldspar and quartz particles detach from the surface of the roll-carrier $\left(F_{\mathrm{i} 2}=F_{\mathrm{c} 2}\right.$; i.e. $\left.f_{2}=1\right)$, the pinning factor for the flat mica flake is $f_{1}=27$. The strong pinning effect $\left(F_{\mathrm{i} 1}=27 F_{\mathrm{c} 2}\right)$ explains the fact that most of the flakes move with the roll-carrier until they are mechanically wiped off by the brush or their charge is electrically neutralised.

The photographs in Fig. 3 suggest that a more realistic assumption is that all the particles have quasi-equal volumes, i.e. $A_{1} h_{1}=A_{2} h_{2}$. Under these circumstances the ratio of the pinning factors is:

$$
f_{1} / f_{2}=\left[\left(A_{1} h_{1}\right) / h_{1}^{4}\right] /\left[\left(A_{2} h_{2}\right) / h_{2}^{4}\right]=1 /\left(h_{1} / h_{2}\right)^{4}
$$

Considering $h_{1} / h_{2}=1 / 3$, as in the example discussed above, it results in $f_{1} / f_{2}=81$. This means that when the value of $f_{2}$ is slightly below one, i.e. the isometric particles of feldspar or quartz detach from the roll then the image force that acts on the mica flakes is almost 81 times stronger than the respective centrifugal force.

The role of the auxiliary corona electrode in Method $I$ is to ensure that $f_{2}$ is slightly below unity at $\alpha=50^{\circ}$, in order to let the feldspar and quartz particles detach from the roll and be collected separately from the mica flakes. By energising this electrode from an adjustable high-voltage supply (the polarity of which is opposite to that of the main electrode), a flux of ions is generated so that the charge on the granules is reduced to a threshold which satisfies the above condition. 


\section{(b) Discussion of Method II}

The electric image force in the case of the dielectric-coated roll-carrier electrode can be written as:

$$
\mathrm{F}_{\mathrm{i}}=(\mathrm{qA})^{2} /\left[4 \pi \epsilon_{\mathrm{o}}(2 \mathrm{~d})^{2}\right]=(\mathrm{qA})^{2} /\left\{4 \pi \epsilon_{\mathrm{o}}\left[2(\mathrm{~h}+\delta)^{2}\right]\right\}
$$

where $\delta$ is the thickness of the dielectric layer. The pinning factor depends not only on the geometry of the particle but also on the value of $\delta$ :

$$
\mathrm{f}=\mathrm{F}_{\mathrm{i}} / \mathrm{F}_{\mathrm{c}}=\left[\mathrm{q}^{2} /\left(64 \pi^{3} \epsilon_{0} \mathrm{n}^{2} \mathrm{R} \gamma\right)\right]\left\{\mathrm{A} /\left[\mathrm{h}(\mathrm{h}+\delta)^{2}\right]\right\}
$$

With $\gamma_{2}=\gamma_{1}=\gamma$, and $k_{1}=k_{2}=k$, the ratio of the pinning factors of flat $\left(f_{1}\right)$ and isometric $\left(f_{2}\right)$ particles is:

$$
f_{1} / f_{2}=\left(A_{1} / A_{2}\right)\left(h_{2} / h_{1}\right)\left(d_{2} / d_{1}\right)^{2}
$$

As in the case of Method I, there are two situations that should be examined. If $A_{1}$ $=A_{2}$, then eq. (10) becomes:

$$
\mathrm{f}_{1} / \mathrm{f}_{2}=\left(\mathrm{h}_{2} / \mathrm{h}_{1}\right)\left(\mathrm{d}_{2} / \mathrm{d}_{1}\right)^{2}=\left(\mathrm{h}_{2} / \mathrm{h}_{1}\right)\left[\left(\mathrm{h}_{2}+\delta\right) /\left(\mathrm{h}_{1}+\delta\right)\right]^{2}
$$

For $h_{1} / h_{2}=1 / 3$ and $\delta=h_{2}$, i.e. $d_{1}=(4 / 3) h_{2}$ and $d_{2}=2 h_{2}$, the pinning factor of mica flakes is $27 / 4$ times that of the other particles.

With a more realistic hypothesis of particles of equal volumes $\left(A_{1} \mathrm{~h}_{1}=A_{2} h_{2}\right)$ the ratio of the pinning factors can be expressed as:

$$
f_{1} / f_{2}=\left(h_{2} / h_{1}\right)^{2}\left(d_{2} / d_{1}\right)^{2}
$$

In the example considered above $\left(h_{1} / h_{2}=1 / 3\right.$ and $\left.\delta=h_{2}\right)$ we have $f_{1} / f_{2}=81 / 4$.

For particles of the same dimensions the ratios of the pinning factors in the case of Method II are smaller than those achieved with Method I (four times smaller in the example considered above). Nevertheless, Method II is at least as efficient as 
Method I. Its advantage is derived from the fact that the superficial conductivity of the particles does not affect the charge carried by them. When the particles are in contact with the metallic roll electrode (Method I) their charge decreases in time, as it may leak to the ground. This cannot occur when the grounded electrode is covered by a dielectric layer (Method II).

\section{CONCLUSIONS}

The two methods of electrostatic shape separation presented in this paper are almost equally efficient for the beneficiation of the flake mica from a particulate mixture containing 50 to $65 \%$ of muscovite. Products of chemical composition close to that of pure muscovite were obtained in a roll-type electroseparator, either by employing an experimental setup with two corona electrodes of opposite polarities conveniently located relative to the metallic roll-carrier (Method I) or, by covering the surface of the grounded electrode with a dielectric layer, and using only one corona electrode (Method II). The former method required a strict control of the superficial conductivity of the particles while the latter was demonstrated to be insensitive to this factor. In both cases, the efficiency of electroseparation increased by restricting the size distribution of the material.

Formulae which give a crude evaluation of the magnitude of the pinning factor (i.e. the ratio between the electric image force and the centrifugal force acting on a particle) proved to be useful in the discussion of the two methods of electrostatic shape separation. It was shown that the pinning factor of flat flakes of mica is much higher than that of isometric particles of feldspar and quartz. This explains feasibility of electroseparation. In the second method of electrostatic shape separation, the pinning effect is stronger if the thickness of the dielectric layer which covers the roll-carrier is smaller.

Laboratory tests demonstrated that a two-stage electroseparation included in the existing industrial flowsheet of pegmatites could ensure a product that would fulfill the requirements regarding the composition and size distribution of the flake mica for several applications in the industry of electroinsulating materials. Further research is needed to optimise the operating conditions and to find the best technical solutions for the manufacture of the dielectric-coated electrode. 


\section{ACKNOWLEDGMENTS}

This work was supported by the grants-in-aid from the Non-Metallic Minerals Co., Cluj-Napoca (Romania), and the Ministry of Science and Technology. Authors express their gratitude to Paul Racatainu, Senior scientist at the Mining R\&D Institute, Cluj-Napoca, for useful discussions., and to Lucian Pop who took the photograph, and to their colleagues Vasile Neamtu and Petru Costel, for their experimental assistance.

\section{REFERENCES}

[1] O.C. Ralston: Electrostatic Separation of Mixed Granular Solids. Elsevier, Amsterdam (1961)

[2] J.E. Lawver and W.P. Dyrenforth: Electrostatic Separation. In: Electrostatics and Its Applications (Ed.: A.D. Moore), J. Wiley, New York (1973), pp. 221-249

[3] C.B. Gill: Materials Beneficiation, Springer, Berlin (1991)

[4] I.I. Inculet: Electrostatic Mineral Separation. J. Wiley, New York (1986)

[5] R. Morar, Al. Yuga and L. Dascalescu: Industrial applications of granular materials separation using corona-electrostatic fields. In: Proc. Int. Conf. El. Machining, Nagoya, Japan (1989), pp. 410-413

[6] J.N. Wilson: Feldspar-mica separation: an unusual flotation flowsheet. Preprint Int. Min. Proc. Congress, London (1960), Paper IV-23

[7] A.I. Mesenjasin: Electroseparation in Intense Fields. Nedra, Moscow (1978), (in Russian)

[8] F.S. Knoll, J.E. Lawver and J.B. Taylor: Electrostatic separation. In: Ullman's Encyclopedia of Industrial Chemistry, VCH, Weinheim (1988), Vol. B2, pp. 20.1-20.11

[9] Al. Yuga, L. Dascalescu, R. Morar, I. Csorvasy and V. Neamtu: Corona electrostatic separators for recovery if waste non-ferrous metals. J. Electrostat. 23 (1989), 235

[10] Al. Yuga et al.: Romanian Patent 101011/1989

[11] L. Dascalescu et al.: Corona and electrostatic electrodes for high-tension separator. J. Electrostat. 29 (1993), 211

Keywords: electrostatic separation, corona field, mica 